\title{
Genetic relationships between diploid and allotetraploid cherry species (Prunus avium, Prunus $\times$ gondouinii and Prunus cerasus)
}

\author{
M Tavaud ${ }^{1,3}$, A Zanetto ${ }^{1}$, JL David ${ }^{2}$, F Laigret ${ }^{1}$ and E Dirlewanger ${ }^{1}$ \\ ${ }^{1} I N R A$, UREFV, BP81, 71, Avenue E Bourleaux, 33883 Villenave d'Ornon, France; ${ }^{2} I N R A$, UMR DGPC, Domaine de Melgueil, 34130 \\ Mauguio, France
}

\begin{abstract}
Prunus avium L. (diploid, AA, $2 n=2 x=16$ ), Prunus cerasus L. (allotetraploïd, AAFF, $2 n=4 x=32$ ) species, and their hybrid Prunus $\times$ gondouinii Rehd., constitute the most widely cultivated cherry tree species. $P$. cerasus is supposed to be an hybrid species produced by the union of unreduced $P$. avium gametes and normal $P$. fruticosa gametes. A continuum of morphological traits between these three species makes their assignation difficult. The aim of this paper is to study the genetic relationships between tetraploid and diploid cherry species. In all, 114 genotypes belonging to these species were analyzed using 75 AFLP markers. The coordinates of these genotypes on the first axis of a
\end{abstract}

correspondence analysis allowed us to clearly distinguish each species, to identify misclassifications and to assign unknown genotypes to one species. We showed that there are specific alleles in $P$. cerasus, which are not present in the A genome of $P$. avium and which probably come from the $\mathrm{F}$ genome of $P$. cerasus. The frequencies of each marker in the $A$ and the $F$ genomes were estimated in order to identify $A$ and $F$ specific markers. We discuss the utility of these specific markers for finding the origin of the $A$ and $F$ genomes in the allopolyploid species.

Heredity (2004) 93, 631-638. doi:10.1038/sj.hdy.6800589

Published online 8 September 2004

Keywords: Prunus avium; Prunus cerasus; AFLP markers; species identification; genetic diversity

\section{Introduction}

The most widely cultivated cherry trees belong to Prunus avium L. and P. cerasus L. species. Along with P. fruticosa Pall., these species and their interspecific hybrids constitute the Eucerasus section of the Cerasus subgenus, based on morphological criteria (Rehder, 1947; Krussmann, 1978). This classification and the monophyletic origin of the Eucerasus clade have been confirmed by chloroplastDNA variation analysis (Badenes and Parfitt, 1995).

$P$. avium includes sweet cherries, cultivated for human consumption and wild cherry trees grown for their wood (Webster, 1996). This species is diploid (AA, $2 n=2 x=16$ ) and its natural range covers the temperate regions of Europe, from the Northern part of Spain to the Southeastern part of Russia (Hedrick, 1915). P. fruticosa, the ground cherry tree, is a tetraploid wild species $(2 n=4 x=32)$ thought to be autotetraploid (FFFF), sometimes used as rootstocks for other Prunus species. This species is widespread over the major part of central Europe, Siberia and Northern Asia (Hedrick, 1915). P. cerasus, the sour cherry tree, is cultivated for fruit, used in jam or liquor. It is an allotetraploid species (AAFF, $2 n=4 x=32$ ), thought to result from natural hybridiza-

Correspondence: Dr M Tavaud, INRA, UREFV, BP81, 71, Avenue E Bourleaux, 33883 Villenave d'Ornon, France.

E-mail: tavaud@ensam.inra.fr

${ }^{3}$ Current address: INRA, UMR DGPC, Domaine de Melgueil, 34130 Mauguio, France.

Received 27 November 2003; accepted 16 July 2004; published online 8 September 2004 tion between $P$. avium (producing unreduced gametes) and P. fruticosa (Figure 1). This origin was first suggested by Olden and Nybom (1968), who observed that artificial hybrids between tetraploid P. avium and P. fruticosa were very similar to $P$. cerasus. Isozyme analyses, genomic in situ hybridization and karyotype analysis further confirmed the hybrid origin of P. cerasus (Hancock and Iezzoni, 1988; Santi and Lemoine, 1990a; Schuster and Schreiber, 2000). The patterns of inheritance of seven isozymes in different crosses of sour cherry indicated that $P$. cerasus may be a segmental allopolyploid (Beaver and Iezzoni, 1993). Recent studies based on cpDNA markers detected two distinct chlorotypes in P. cerasus, which strongly suggest that crosses between P. avium and $P$. fruticosa have occurred at least twice to produce sour cherry (Badenes and Parfitt, 1995; Iezzoni and Hancock, 1996; Brettin et al, 2000). Moreover, these results suggest that, most of the time, $P$. fruticosa was the female progenitor of $P$. cerasus, but in few cases $P$. avium was the female parent, via the formation of unreduced ovules. Triploid hybrids through the fusion of normal gametes of $P$. avium and $P$. fruticosa occur naturally but remain sterile. Moreover, they are not clonally propagated by man since they exhibit many unfavorable $P$. fruticosa traits (Olden and Nybom, 1968).

The duke cherries, which result from crosses between $P$. avium and P. cerasus, are cultivated at much smaller scale. Different names have been given to this species including $P$. acida Dum, Cerasus regalis, $P$. avium $\mathrm{ssp}$ regalis, but the name used currently is $P . \times$ gondouinii Rehd. (Faust and Suranyi, 1997; Saunier and Claverie, 2001). This species is allotetraploid (AAAF, $2 n=4 x=32$ ), 


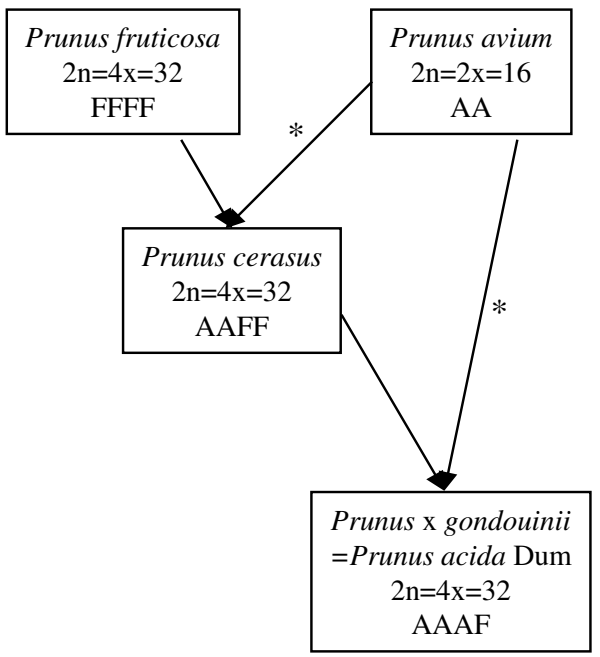

Figure 1 Hypothesis for the relationships between the four species belonging to the Eucerasus section. *P. avium is thought to produce diploid gametes. A and $\mathrm{F}$ are haploid genomes coming from $P$. avium and $P$. fruticosa respectively.

stemming from the fertilization of sour cherry by unreduced gametes of sweet cherry (Iezzoni et al, 1990). These hybrids are often sterile, due to disturbances during meiosis, but they are clonally propagated by man. The duke cherry trees present tree and fruit characteristics intermediate between their progenitors.

Great morphological variation exists among P. avium, $P$. fruticosa and $P$. cerasus species. Multivariate analysis on sour cherry revealed continuous variation between the $P$. avium, $P$. cerasus and $P$. fruticosa traits throughout the geographic distribution of the species. In Western Europe, $P$. cerasus trees look like $P$. avium, whereas in Eastern Europe P. cerasus are closer to P. fruticosa (Hillig and Iezzoni, 1988; Krahl et al, 1991). This continuum of morphological characteristics makes species assignation difficult when considering only phenotypic traits.

Genetic resource conservation, essential for future breeding programs, requires a good characterization of germplasm genetic diversity and a proper assignation of individual genotypes to species. Molecular markers supply tools to analyze genetic diversity in Prunus species (Baird et al, 1996). They could be helpful by giving an accurate and unambiguous assignation of each genotype to a particular species. Isozymes have been already used to characterize genetic diversity in $P$. avium and P. cerasus, but the number of available isozymes is limited and their polymorphisms are low (Santi and Lemoine, 1990b). AFLP markers could be useful because they are reproducible, they need no previous information about the genome and they allow the detection of many markers in few analysis (Vos et al, 1995; Jones et al, 1997). They are well suited for studying unexplored species and have already been used successfully to discriminate different species with varying ploidy levels in Gossypium and Oryza (Aggarwal et al, 1999; Abdalla et al, 2001).

The aim of this work was first to determine whether AFLP markers could be useful in assigning each cherry genotype accurately to one species ( $P$. avium, $P$. cerasus or $P . \times$ gondouinii). We also wanted to find specific markers of the different genomes ( $\mathrm{A}$ and $\mathrm{F}$ ) of these cherry species. These markers would be useful for comparing the diversity of the A genome between $P$. avium and $P$. cerasus and to identify the origin of the A genome in both tetraploid species $(P$. cerasus and $P . \times$ gondouinii).

\section{Materials and methods}

\section{Plant material}

In all, 114 genotypes were studied: 68 P. avium genotypes (33 cultivated and 35 wild) sampled throughout the natural range of the species, 25 P. cerasus genotypes and 9 $P . \times$ gondouinii genotypes according to morphological characters (Table 1). In total, 12 French genotypes which had not been previously studied were not assigned to a species. The 33 cultivated sweet cherry trees were old cultivars, from 13 different countries. The 35 wild cherry trees were from several European forests. Sour and duke cherry trees and unassigned genotypes were from the French germplasm, mainly maintained in INRA orchards, at the 'Unité Expérimentale d'Arboriculture de Bordeaux'.

\section{AFLP analyses}

Genomic DNA was extracted from young leaves, following the method described by Viruel et al (1995). We essentially followed the AFLP protocol developed by Vos et al (1995) with minor modifications. DNA was digested with EcoRI and MseI restriction enzymes. Digestion was performed for $4 \mathrm{~h}$ at $37^{\circ} \mathrm{C}$ in a final volume of $17.5 \mu \mathrm{l}$ containing $10 \mathrm{mM}$ Tris-Ac, $10 \mathrm{mM} \mathrm{MgAc,} 50 \mathrm{mM} \mathrm{KAc}$, $5 \mathrm{mM}$ DTT, 25U EcoRI (Pharmacia), $4 \mathrm{U}$ MseI (New England Biolabs) and $250 \mathrm{ng}$ of genomic DNA. Two linkers, one for the EcoRI sticky ends and the other for the MseI sticky ends, were ligated for $3 \mathrm{~h}$ at $37^{\circ} \mathrm{C}$ to the digested DNA by adding $2.5 \mu \mathrm{l}$ of a mix containing 2.5 pmol EcoRI linker, $25 \mathrm{pmol}$ MseI linker, $8 \mathrm{mM}$ ATP, $10 \mathrm{mM}$ Tris-HAc, $10 \mathrm{mM} \mathrm{MgAc}, 50 \mathrm{mM}$ KAc, $5 \mathrm{mM}$ DTT and $0.85 \mathrm{U}$ T4 DNA ligase (Pharmacia). This ligation product was diluted five-fold. A first preselective PCR amplification was performed using EcoRI $+\mathrm{A}$ and MseI + $\mathrm{C}$ primers in a $50 \mu \mathrm{lmix}$ of $20 \mathrm{mM}$ Tris- $\mathrm{HCl}(\mathrm{pH} 8.4)$, $50 \mathrm{mM} \mathrm{KCl}, 1.5 \mathrm{mM} \mathrm{MgCl}_{2}, 0.2 \mathrm{mM}$ of each dNTP, $30 \mathrm{ng}$ of each primer, $1 \mathrm{U}$ Taq DNA polymerase (GibcoBRL) and $5 \mu \mathrm{l}$ of diluted ligation product. The reaction was carried out in a Perkin-Elmer 9600 thermocycler and the samples were subjected to 28 amplification cycles with three steps of $30 \mathrm{~s}$ at $94^{\circ} \mathrm{C}, 60 \mathrm{~s}$ at $56^{\circ} \mathrm{C}$ and $60 \mathrm{~s}$ at $72^{\circ} \mathrm{C}$. The preamplification products were diluted 10-fold and used as starting material for the selective radioactive amplification.

For selective amplification, EcoRI and MseI primers with three and two additional nucleotides, respectively, were used (Table 2), the first one being ${ }^{33}$ P-labelled using $\mathrm{T}_{4}$ polynucleotide kinase. The PCR reaction was performed in a $20 \mu \mathrm{l}$ volume of $20 \mathrm{mM}$ Tris- $\mathrm{HCl}(\mathrm{pH} 8.4)$, $50 \mathrm{mM} \mathrm{KCl}, 1.5 \mathrm{mM} \mathrm{MgCl}_{2}, 5 \mathrm{ng}\left[{ }^{33} \mathrm{P}\right]$ EcoRI primer, $30 \mathrm{ng}$ MseI primer, $1 \mathrm{U}$ Taq DNA polymerase (GibcoBRL) and $5 \mu \mathrm{l}$ of diluted preamplified DNA. The selective amplification was carried out using the following cycling parameters: 11 cycles of $30 \mathrm{~s}$ at $94^{\circ} \mathrm{C}, 30 \mathrm{~s}$ at $65^{\circ} \mathrm{C}, 60 \mathrm{~s}$ at $72^{\circ} \mathrm{C}$, in which the annealing temperature was lowered by $0.7^{\circ} \mathrm{C}$ per cycle, followed by 24 cycles of $30 \mathrm{~s}$ at $94^{\circ} \mathrm{C}$, $30 \mathrm{~s}$ at $56^{\circ} \mathrm{C}$ and $60 \mathrm{~s}$ at $72^{\circ} \mathrm{C}$.

The PCR products, in which an equal volume of load buffer (98\% formamide, $10 \mathrm{mM}$ EDTA, $0.05 \%$ bromophenol blue and $0.05 \%$ xylene cyanol) had been added, were denatured $5 \mathrm{~min}$ at $94^{\circ} \mathrm{C}$ and immediately placed on ice. In all, $2 \mu \mathrm{l}$ of each sample was loaded on a 
Table 1 (a) A priori species assignation, geographical origin and sample number of the cultivated and wild genotypes studied. (b) Names of cherry varieties analysed and their species assignation according to their coordinates on the first axis of the factorial analysis

\begin{tabular}{|c|c|c|c|c|c|c|}
\hline \multicolumn{7}{|l|}{$(a)^{\mathrm{a}}$} \\
\hline \multirow[t]{2}{*}{ P. avium priori assignations } & \multirow[t]{2}{*}{ Geographical origin } & \multicolumn{2}{|c|}{ Sample number } & \multicolumn{3}{|c|}{ P. avium posteriori assignations } \\
\hline & & Cultivated cherry & Wild cherry & P. av & P. gon & P. cer \\
\hline \multirow[t]{18}{*}{ P. avium } & Czech republic & 3 & & 3 & & \\
\hline & Canada & 1 & & 1 & & \\
\hline & France & 10 & 8 & 14 & 4 & \\
\hline & Germany & 3 & 5 & 8 & & \\
\hline & Georgia & & 4 & 4 & & \\
\hline & Great Britain & 2 & 2 & 4 & & \\
\hline & Greece & 2 & & 2 & & \\
\hline & Italy & 3 & 5 & 5 & 3 & \\
\hline & Japan & 1 & & 1 & & \\
\hline & Poland & 1 & & 1 & & \\
\hline & Romania & 2 & 3 & 5 & & \\
\hline & Slovakia & & 1 & 1 & & \\
\hline & Spain & & 5 & 3 & & 2 \\
\hline & Sweden & & 2 & 2 & & \\
\hline & Switzerland & 2 & & 2 & & \\
\hline & USA & 1 & & 1 & & \\
\hline & Yugoslavia & 2 & & 1 & & 1 \\
\hline & Total & 33 & 35 & 58 & 7 & 3 \\
\hline P. cerasus & France & 25 & & 2 & 2 & 21 \\
\hline P. $\times$ goundouinii & France & 9 & & 2 & 3 & 4 \\
\hline Undetermined genotypes & France & 12 & & 2 & 4 & 6 \\
\hline Total & & & 114 & & & \\
\hline
\end{tabular}

(b)

\begin{tabular}{|c|c|c|c|}
\hline Variety names & Origin & a priori assignation & a posteriori assignation \\
\hline Bigarreau Pelissier & France & P. avium & P. avium \\
\hline Guigne noire Luisante & France & P. avium & P. avium \\
\hline Cœur de Bœuf & France & P. avium & P. avium \\
\hline Koromilokeraso Vitalou & Greece & P. avium & P. avium \\
\hline Petrokeraso Tragano Achaias & Greece & P. avium & P. avium \\
\hline Pivovka & Czech republic & P. avium & P. avium \\
\hline Chlumecka cerna & Czech republic & P. avium & P. avium \\
\hline Sakvicka & Czech republic & P. avium & P. avium \\
\hline Bigarreau Cœur de Noyon & France & P. avium & P. avium \\
\hline Knauffs Schwarze & Germany & P. avium & P. avium \\
\hline Karina & Germany & P. avium & P. avium \\
\hline Büttners Rote Knorpelkirsche & Germany & P. avium & P. avium \\
\hline Bedford Prolific $P$. avium & Great Britain & P. avium & P. avium \\
\hline Nutberry Black & Great Britain & P. avium & P. avium \\
\hline Camus & France & P. avium & P. avium \\
\hline Vittoria & Italy & P. avium & P. avium \\
\hline Maru Ruby ${ }^{\mathbb{R}}$ & USA & P. avium & P. avium \\
\hline Van 2D 9-11 & Canada & P. avium & P. avium \\
\hline Amar 153 & Yugoslavia & P. avium & P. avium \\
\hline Bianca di Verona & Italy & P. avium & P. avium \\
\hline Sato Nishiki & Japan & P. avium & P. avium \\
\hline Arodel & France & P. avium & P. avium \\
\hline Kunzego & Poland & P. avium & P. avium \\
\hline Silva & Romania & P. avium & P. avium \\
\hline Roz Amar de Màrculesti (RAM) & Romania & P. avium & P. avium \\
\hline Ravenna & Italia & P. avium & P. avium \\
\hline Frühe Luxburger & Switzerland & P. avium & P. avium \\
\hline Webers Sämpling & Switzerland & P. avium & P. avium \\
\hline Marasca & Yugoslavia & P. avium & P. cerasus \\
\hline Gros Guin de Cœur & France & P. avium & P. $\times$ gondouinii \\
\hline Guigne Boissière & France & P. avium & P. $\times$ gondouinii \\
\hline Guin des Charentes & France & P. avium & P. $\times$ gondouinii \\
\hline Meynard & France & P. avium & P. $\times$ gondouinii \\
\hline Frumi & Canada & P. cerasus & P. avium \\
\hline Griotte jaune d'Ollins & France & P. cerasus & P. avium \\
\hline Ferracida & France & P. cerasus & P. cerasus \\
\hline Montmorency1 & France & P. cerasus & P. cerasus \\
\hline Montmorency2 & France & P. cerasus & P. cerasus \\
\hline Griotte de Moissac & France & P. cerasus & P. cerasus \\
\hline Griotte Layat & France & P. cerasus & P. cerasus \\
\hline
\end{tabular}


Table 1 (continued)

\begin{tabular}{|c|c|c|c|}
\hline Variety names & Origin & a priori assignation & a posteriori assignation \\
\hline Griotte du Nord & France & P. cerasus & P. cerasus \\
\hline Montmorency3 & France & P. cerasus & P. cerasus \\
\hline Acide Haut Rhin1 & France & P. cerasus & P. cerasus \\
\hline Acide Haut Rhin2 & France & P. cerasus & P. cerasus \\
\hline Acide Haut Rhin3 & France & P. cerasus & P. cerasus \\
\hline Cerise de Toussaint & France & P. cerasus & P. cerasus \\
\hline Grinque Montmorency & France & P. cerasus & P. cerasus \\
\hline Griotte précoce & France & P. cerasus & P. cerasus \\
\hline Montmorency pleureur de Sauvigny & France & P. cerasus & P. cerasus \\
\hline Iwa & Poland & P. cerasus & P. cerasus \\
\hline Sabina & Poland & P. cerasus & P. cerasus \\
\hline Lucyna & Poland & P. cerasus & P. cerasus \\
\hline Cerise acide Mimbielle & France & P. cerasus & P. cerasus \\
\hline Griotte de Moissac & France & P. cerasus & P. cerasus \\
\hline Montmorency4 & France & P. cerasus & P. cerasus \\
\hline Griotte du Lyonnais & France & P. cerasus & P. cerasus \\
\hline Griotte de Provence & France & P. cerasus & P. $\times$ gondouinii \\
\hline Guigne Boissière & France & P. cerasus & P. $\times$ gondouinii \\
\hline Anglaise Hative1 & France & P. $\times$ gondouinii & P. avium \\
\hline Anglaise Hative2 & France & P. $\times$ gondouinii & P. avium \\
\hline Cerise Olivet Hative & France & P. $\times$ gondouinii & P. cerasus \\
\hline Cerise Olivet Tardive & France & P. $\times$ gondouinii & P. cerasus \\
\hline Cerise Reine Hortense & France & P. $\times$ gondouinii & P. cerasus \\
\hline Belle Magnifique & France & P. $\times$ gondouinii & P. cerasus \\
\hline Cerise Impératrice Eugénie & France & P. $\times$ gondouinii & P. $\times$ gondouinii \\
\hline Gros guin noir de Gironde & France & P. $\times$ gondouinii & P. $\times$ gondouinii \\
\hline Maynard & France & P. $\times$ gondouinii & P. $\times$ gondouinii \\
\hline La Carrée & France & unknown & P. avium \\
\hline Petite joue vermeille & France & unknown & P. avium \\
\hline Belle de Varennes & France & unknown & P. cerasus \\
\hline Grosse cerise tardive & France & unknown & P. cerasus \\
\hline Grosse griotte & France & unknown & P. cerasus \\
\hline Triaux de Fondettes & France & unknown & P. cerasus \\
\hline Belle Magnifique & France & unknown & P. cerasus \\
\hline Cerise Royale Tardive & France & unknown & P. cerasus \\
\hline Cerise Cure1 & France & unknown & P. $\times$ gondouinii \\
\hline Cerise Cure2 & France & unknown & P. $\times$ gondouinii \\
\hline Guin des Charentes & France & unknown & P. $\times$ gondouinii \\
\hline
\end{tabular}

${ }^{a}$ A posteriori species repartition of genotypes in the three species was determined according to their coordinates on the first axis of the factorial analysis. For each species, total numbers are indicated in bold.

polyacrylamide gel (4.5\% acrylamide/bisacrylamide $20: 1$, $7.5 \mathrm{M}$ Urea and $0.5 \times \mathrm{TBE}$ ) and were run at $95 \mathrm{~W}$ for $2 \mathrm{~h}$ After electrophoresis, gels were dried on a standard slab gel drier for $2 \mathrm{~h}$ and exposed for 5 days to an X-ray film. Each analysis was performed twice for each individual.

Only intense, polymorphic and reproducible bands were taken into account to generate a binary matrix $0-1$, where 1 and 0 denote, respectively, the presence and the absence of a band.

\section{Statistical analyses}

Species assignation: To properly assign based genotypes to their species, a correspondence analysis based on the AFLP markers was first performed on the whole sample using the procedure CORRESP of the SAS software (SAS Intitute, 1985). An a posteriori species group was assigned to each genotype according to its coordinates on the first axis of this analysis.

Variation of individual band number (IBN): As AFLP markers are dominant, the phenotype [1] corresponds either to the genotype (11) or to the genotypes (01) or (10), whereas phenotype [0] is only due to the (00) genotype. Let $q_{i}$ be the frequency of allele 0 at locus $i$ in one species. If we assume that this species can be
Table 2 Sequences of the primers used for AFLP selective amplification and number of reducible polymorphic bands analysed

\begin{tabular}{|c|c|c|}
\hline $\begin{array}{l}\text { EcoRI/MseI } \\
\text { primers }\end{array}$ & Primer sequences & $\begin{array}{c}\text { Number of } \\
\text { markers }\end{array}$ \\
\hline EcoRI+AGG & 5'-GACTGCGTACCAATTCAGG-3' & 20 \\
\hline$/ M s e \mathrm{I}+\mathrm{CA}$ & $5^{\prime}$-GATGAGTCCTGAGTAACA- $3^{\prime}$ & \\
\hline EcoRI+AGG & 5'-GACTGCGTACCAATTCAGG-3' & 17 \\
\hline /MseI+CG & 5'-GATGAGTCCTGAGTAACG-3' & \\
\hline EcoRI+AAC & 5'-GACTGCGTACCAATTCAAC-3' & 22 \\
\hline /MseI+CG & 5'-GATGAGTCCTGAGTAACG-3' & \\
\hline EcoRI+AGA & 5'-GACTGCGTACCAATTCAGA-3' & 16 \\
\hline$/ \mathrm{MseI}+\mathrm{CA}$ & 5'-GATGAGTCCTGAGTAACA-3' & \\
\hline Total & & 75 \\
\hline
\end{tabular}

considered as being at Hardy-Weinberg equilibrium (random mating, nonoverlapping generations, large population size, mutation ignored and migration overlooked), this allelic frequency $q_{i}$ can be estimated by $\hat{q}_{i}^{2}=[0]$ in a diploid species and by $\hat{q}_{i}^{4}=[0]$ in an autotetraploid species, where [0] is the frequency of the phenotype [0] for the locus $i$. Allele frequencies were calculated following this method for each locus in diploid P. avium species. 
We wanted to know whether an increase of IBN in tetraploid $P$. cerasus species (AAFF), in comparison to $P$. avium, a diploid species (AA), was simply due to polyploidization or could be attributed to specific markers belonging to the $\mathrm{F}$ genome. Indeed, autopolyploidization increases IBN since the frequency of the phenotype [1] is $1-q_{i}^{4}$ in a putative autotetraploid species, whereas this frequency is $1-q_{i}^{2}$ in diploid species for each locus. IBN was calculated as the sum of all amplified bands [1] in each genotype considering all the AFLP markers. To determine the effect of autopolyploidization on the IBN, we simulated 500 autotetraploid genotypes (AAAA), formed by the autotetraploidization of $P$. avium with identical allelic frequencies $q_{i}$ to $P$. avium. For each simulated genotype, the phenotype at each locus $i$ was randomly assigned to [0] or [1] with probabilities $\hat{q}_{i}^{4}$ and $1-\hat{q}_{i}^{4}$, respectively, where $\hat{q}_{i}$ is the estimated allele 0 frequency in $P$. avium. The mean value of the IBN, in each species, is computed as $\sum_{1}^{i=75}\left(1-\hat{q}_{i}^{2}\right)$ in diploid species, and $\sum_{1}^{i=75}\left(1-\hat{q}_{i}^{4}\right)$ in tetraploid species, where $i$ denotes the locus, $\hat{q}_{i}$ the allele 0 frequency in the species. We compared the IBN distribution in $P$. avium, the 'simulated' autotetraploid species, $P$. cerasus and $P . \times$ gondouinii.

Determination of genome-specific markers: To compare genetic diversity in each genome, among species with different ploidy levels, the determination of genomespecific markers is needed. In an allotetraploid species like $P$. cerasus (AAFF), markers could be present specifically in one genome or in both genomes. We cannot distinguish if the phenotype [1] in P. cerasus is due to marker amplification in $\mathrm{A}$ or/and $\mathrm{F}$ genome. We estimated allele frequencies of each marker in the $\mathrm{A}$ and $\mathrm{F}$ genomes in order to detect $\mathrm{A}$ and $\mathrm{F}$ genome-specific markers. Let $q_{\mathrm{A}_{i}}$ be the frequency of the allele 0 in the $P$. avium genome at the locus $i$ and let $q_{\mathrm{F}_{i}}$ be the frequency of the allele 0 in the $\mathrm{F}$ genome of $P$. cerasus brought by $P$. fruticosa through allopolyploidization. Thus, markers for which $q_{\mathrm{F}_{i}}=1$ are specific to the A genome (no amplification in $\mathrm{F}$ genome because the allele 0 is fixed), whereas markers for which $q_{\mathrm{A}_{i}}=1$ are specific to the $\mathrm{F}$ genome markers. Assuming that $P$. avium is at HardyWeinberg equilibrium, the allelic frequency $q_{\mathrm{A}_{i}}$ was estimated by $\hat{q}_{\mathrm{A}_{i}}=\sqrt{[0]_{\text {avium }}}$, where $[0]_{\text {avium }}$ is the frequency of the phenotype [0] in P. avium. Several assumptions have to be made to carry on the estimation of $q_{\mathrm{F}_{i}}$, that is, to identify specific markers. We first assumed that both $P$. avium and $P$. cerasus are weakly spatially structured and that their allelic frequencies are still close to their initial state (ie before the allopolyploidization event). Under these hypotheses, $q_{\mathrm{A}_{i}}$ in $P$. avium and in $P$. cerasus should be closely related. Thus, in $P$. cerasus, $[0]_{\text {cerasus }}=\hat{q}_{\mathrm{F}_{i}}^{2} \hat{q}_{\mathrm{A}_{i}}^{2}$, where $[0]_{\text {cerasus }}$ is the frequency of the phenotype [0] in this species. For each locus, $q_{\mathrm{F}_{i}}$ was estimated as $\hat{q}_{\mathrm{F}_{i}}=\sqrt{[0]_{\text {cerasus }} / \hat{q}_{\mathrm{A}_{i}}^{2}}$. Many $\hat{q}_{\mathrm{F}_{i}}$ were higher than 1, indicating that the real frequency $q_{\mathrm{A}_{i}}$ in $P$. cerasus is lower than in $P$. avium for these loci; these markers are clearly A genome specific and we considered that $\hat{q}_{\mathrm{F}_{i}}=1$. For each marker, we plotted the frequencies $\hat{q}_{\mathrm{F}_{i}}$ versus $\hat{q}_{\mathrm{A}_{i}}$.

Genetic diversity of the A genome in $P$. avium and $P$. cerasus: P. cerasus comes from crosses between P. avium and $P$. fruticosa. We wanted to know whether the genetic diversity of the A genome is lower in P. cerasus than in $P$. avium. To estimate genetic diversity in the two species, we used average heterozygosity (He), also known as gene diversity (Nei, 1978). Using only A genome-specific markers, we computed $\mathrm{He}$ as $\mathrm{He}_{i}=2 q_{i}\left(1-q_{i}\right)$, where $q_{i}$ is the frequency of allele 0 at locus $i$ in the species studied. In $P$. avium, such frequency is $q_{\mathrm{A}_{i}}$, whereas in $P$. cerasus, this frequency is calculated by $q_{\mathrm{A}_{i} \text { cerasus }}=\sqrt{[0]_{\text {cerasus }}}$ using only A-specific markers. For each species, we calculated $\mathrm{He}$ as the mean of $\mathrm{He}_{i}$. We computed $\mathrm{He}_{i \text { avium }}-\mathrm{He}_{i \text { cerasus }}$ for each locus and tested the mean difference using a sign test.

\section{Results}

\section{Species assignation}

A total of 75 polymorphic AFLP markers were detected using the four primer pairs, as indicated in Table 2. On the two first axes of the correspondence analysis based on the 75 AFLP markers, three clear-cut groups appeared (Figure 2). The first axis corresponds to $31.5 \%$ of total inertia. The $P$. cerasus and $P$. avium genotypes mainly compose the two extreme groups with some misclassified individuals. In the $P$. avium group, one Canadian variety and one old French variety were $a$ priori declared as belonging to $P$. cerasus; two old French varieties were previously classified as $P . \times$ gondouinii (Table 1 ). The $P$. cerasus group contains three and four genotypes previously classified as $P$. avium and $P$. $\times$ gondouinii, respectively. The intermediate group contains nine misidentifications (seven presumed $P$. avium and two $P$. cerasus), four undefined genotypes and only three genotypes identified as $P . \times$ gondouinii. The coordinates on the first axis of the factorial analysis allow to clearly assign $a$ posteriori each genotype to one species, that is, to

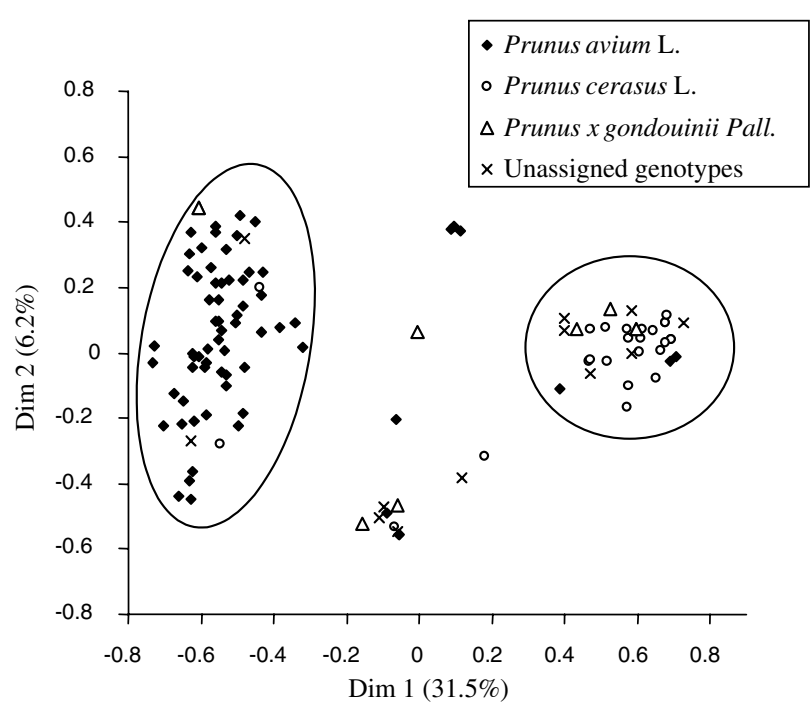

Figure 2 Coordinates of correspondence analysis on 75 AFLP markers of 114 genotypes on the two first axes. Symbols indicate $a$ priori assignation genotypes, based on morphological descriptors. The two first axes represent $36.7 \%$ of total variation. Each genotype with coordinates on the first axis lower than -0.3 is a posteriori classified in P. avium species; each genotype with coordinates up to 0.3 is $P$. cerasus genotype, and each genotype with coordinates between -0.3 and 0.3 is $P$. $\times$ gondouinii genotype. 
classify unknown genotypes in one species and to correct misidentifications as summarized in Table 1. Each sample having a coordinate on the first axis lower than -0.3 was classified as $P$. avium species; each sample with a coordinate higher than 0.3 was classified as $P$. cerasus genotype. Between these two groups, intermediate genotypes are classified in $P . \times$ gondouinii species. With the 75 markers used, we detected five pairs of identical genotypes: one pair of $P$. cerasus, two pairs previously classified in $P$. avium (a posteriori $P . \times$ gondouinii) and two pairs previously classified in $P . \times$ gondouinii (a posteriori $P$. avium and $P$. cerasus). These five pairs have thus the same coordinates on the two first axes of the factorial analysis and are consequently merged in Figure 2.

The second axis, corresponding to $6.2 \%$ of total inertia, gives information on intraspecific variation. An analysis of the three species separately did not show clear genetic structure in P. avium or in P. cerasus. However, among the $P . \times$ gondouinii genotypes, we noticed three distinct groups also distinguishable in the global factorial analysis, one composed of Italian genotypes previously classified as $P$. avium and the two others were French varieties (data not shown). Using the a posteriori classification, 61 markers $(81.33 \%)$ of the 75 used are polymorphic in P. avium, 55 markers $(73.33 \%)$ are polymorphic in $P$. cerasus and $52(69.33 \%)$ are polymorphic in P. $\times$ gondouinii. Thus, the allelic richness is highest in $P$. avium.

\section{Variation of IBN among the different species}

When using this a posteriori species classification, the species means of IBN are very different between species: 28.8 and 50.2 for P. avium and P. cerasus, respectively, and 36.6 for the simulated autotetraploid species (AAAA), far less than values from $P$. cerasus (data not shown). The difference in IBN between this 'simulated autotetraploid' and $P$. cerasus means that the number of markers observed in $P$. cerasus may not be explained by doubling chromosome number alone but may be also due to additional alleles, specific to the second genome of $P$. cerasus, that is, the genome coming from $P$. fruticosa. This supports the hypothesis of the allopolyploid origin of $P$. cerasus and suggests that indeed specific alleles come from the $\mathrm{F}$ genome. The $P . \times$ gondouinii genotypes have a mean IBN value of 38.6, which is intermediate between $P$. avium and $P$. cerasus IBNs.

\section{Identification of genome-specific markers}

To detect genome-specific markers, we plotted $\hat{q}_{\mathrm{F}}$ versus $\hat{q}_{\mathrm{A}}$, the estimated allele frequencies of the 75 markers in the $\mathrm{F}$ and the $\mathrm{A}$ genomes, respectively. It was then possible to distinguish five classes of markers (Figure 3):

- Class 1: When $\hat{q}_{\mathrm{F}} \geq 1$ and $0<\hat{q}_{\mathrm{A}}<1$, these markers are always absent in the $\mathrm{F}$ genome and polymorphic in the A genome; these 25 markers are called A-specific markers.

- Class 2: When $\hat{q}_{\mathrm{A}}=1$ and $0<\hat{q}_{\mathrm{F}}<1$, these markers are always absent in the A genome and are polymorphic in the $\mathrm{F}$ genome. These 14 markers are F-specific.

- Class 3: When $\hat{q}_{\mathrm{F}}=0$ and $0<\hat{q}_{\mathrm{A}}<1$, these 10 markers are fixed in the $\mathrm{F}$ genome and they are polymorphic in the A genome.

- Class 4: There are five markers for which $\hat{q}_{\mathrm{F}}=0$ and $\hat{q}_{\mathrm{A}}=1$. They are $\mathrm{F}$ genome diagnostic markers in our

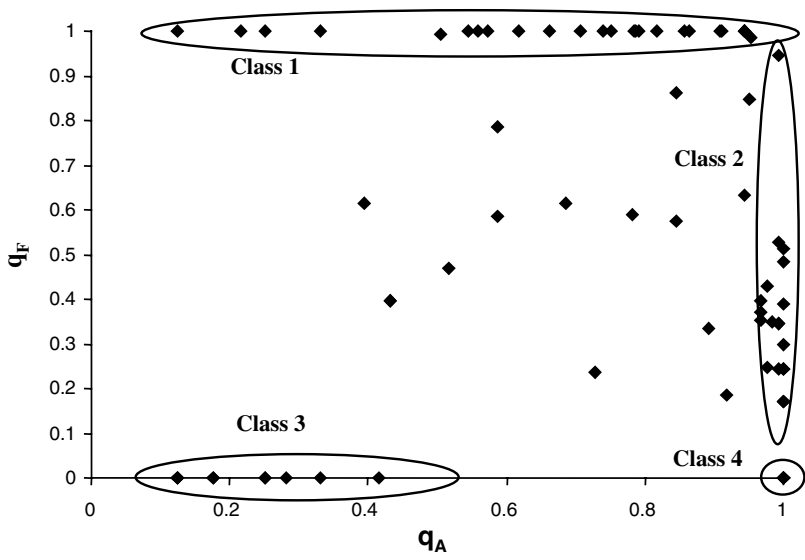

Figure 3 Frequencies of the absent allele (0) for the 75 AFLP markers in P. avium genome $\left(q_{\mathrm{A}}\right)$ versus in F genome in P. cerasus $\left(q_{\mathrm{F}}\right)$. Class 1 contains AFLP markers specific to the A genome, class 2 contains AFLP markers specific to the F genome. Class 3 contains AFLP markers fixed in the F genome of $P$. cerasus and polymorphic in P. avium and class 4 is composed of five markers always found in the $\mathrm{F}$ genome of $P$. cerasus species but never in P. avium species.

sample, that is, they are always present in the $\mathrm{F}$ genome and always absent in the A genome.

- Class 5: When $0<\hat{q}_{\mathrm{F}}<1$ and $0<\hat{q}_{\mathrm{A}}<1$, these 21 markers show polymorphism on both genomes.

With the A- and F-specific markers, the $P . \times$ gondouinii genotypes analyzed are separated in three and two groups, respectively, indicating that there could have been at least three origins of the A genome and two origins of the $\mathrm{F}$ genome in their hybrid species. This suggests that crosses between $P$. avium and P. cerasus may occur recurrently.

\section{Comparison of genetic diversity in A genome between $P$. avium and $P$. cerasus}

Gene diversity (He) is 0.319 in $P$. avium and 0.173 in $P$. cerasus using only the 25 genome A-specific markers. The difference $\mathrm{He}_{i}$ avium $-\mathrm{He}_{i}$ cerasus is positive for 21 markers among the 25 used, and is therefore highly significant using a sign test $(P<0.001)$.

\section{Discussion}

\section{Species assignation}

Using AFLP markers, the three species P. avium, P. cerasus and $P . \times$ gondouinii are clearly distinguished according to their coordinates on the first axis of the correspondence analysis. This separation was confirmed using 725 genotypes of $P$. avium, representing the whole natural range of this species (data not shown). Beaver et al (1995) analyzed seven isozymes markers on $36 P$. cerasus, $P$. avium and $P$. fruticosa and their hybrids. They identified F-specific markers and showed that the first principal coordinate of the PCO clearly separates the diploid from the tetraploid species, but we were not able to distinguish each species in the tetraploid species group.

AFLP markers are good tools for cherry species identification, especially to clearly distinguish tetraploids. Microsatellite markers have been recently developed in P. avium species (Schueler et al, 2003 ) or 
developed in other Prunus species and used in P. avium (Wunsch and Hormaza, 2002). These microsatellite markers are codominant and should be useful for the study of genetic diversity in specific components of the genome, particularly if primers which only amplify a product from one particular genome can be found.

Several phenomena could explain the number of misidentifications in our sample. Many cherry genotypes in this study were old cherry trees, maintained in national orchards and only few morphological traits were observed for species assignment. Moreover, the distinction between $P$. avium and $P$. cerasus species may not be easy, especially during winter (Hillig and Iezzoni, 1988). The morphological continuum between $P$. avium and $P$. cerasus could be due to the range of cold selection among geographical areas (Iezzoni and Mulinix, 1992) and to complex back-crosses occurring with the local progenitor species (Beaver et al, 1995). The identification of $P . \times$ gondouinii is still more difficult because of its phenotypic variability, which ranges from $P$. cerasus to $P$. avium morphologic traits.

Specific markers of the $\mathrm{F}$ genome have been identified using the frequency of the different markers in both genomes of $P$. cerasus. The diagnostic markers (designated 4 in Figure 3), always present in $\mathrm{F}$ genome of $P$. cerasus and always absent in $P$. avium genome in our sample, will now be helpful to detect if a genotype contains the F genome. These could be used for species discrimination, especially to sort $P$. avium from P. $\times$ gondouinii. It would therefore be beneficial to transform the AFLPs into SCAR markers, to allow efficient analysis of a large number of genotypes (Xu et al, 2001).

Genetic resources characterization, management and conservation are essential for future breeding programs. As species assignation based only on morphological traits could lead to misidentifications, we demonstrated that this assignation could efficiently be carried out with AFLP markers. Moreover, the same AFLP analysis could be used to fingerprint varieties and then to assess the genetic diversity present in germplasms, to detect redundant genotypes in order to constitute and conserve a core collection.

\section{Origin of $P$. cerasus}

The difference in distribution of the IBN in $P$. cerasus compared to a simulated theoretical autotetraploid (AAAA) indicates that $P$. cerasus is an allotetraploid containing another genome that is differentiated from the A genome. This fact is in agreement with previous studies indicating that the $P$. cerasus origin was a cross between $P$. avium and P. fruticosa (Olden and Nybom, 1968). The presence of 46 genome-specific markers and only 29 markers detected in both the A and F genomes demonstrates that these two genomes are quite divergent but also that some regions of these genomes are conserved, which is in accordance with the segmental allopolyploidy proposed by Beaver and Iezzoni (1993).

The reduction of genetic diversity observed in the genome $\mathrm{A}$ of $P$. cerasus in comparison with $P$. avium is probably due to the constitution of $P$. cerasus involving only a part of $P$. avium genetic diversity. However, in this work, mainly French sour cherry trees were analyzed. Therefore, these results have to be confirmed using a representative sample of whole $P$. cerasus genetic diversity.

The original habitat of wild P. cerasus is currently unknown and is difficult to determine because many feral forms have escaped from orchards. It is not possible, therefore, to determine a priori which populations of $P$. avium contributed to the A genome of $P$. cerasus. The national ranges of $P$. avium and $P$. fruticosa overlap around the Caspian Sea and Asia Minor; wild $P$. cerasus could be assumed to have appeared in this sympatric area (De Candolle, 1883; Hedrick, 1915). The genome-specific markers detected in our study could be very useful for studying the evolution of one genome among different species with different ploidy levels. We tried to use A genome-specific markers to study the origin of the A genome of $P$. cerasus, that is, to determine which population(s) of $P$. avium has contributed to the constitution of $P$. cerasus. Our inability to unambiguously define the origin of the A genome of $P$. cerasus is probably due to the low number of $P$. avium genotypes in our sample, which is not large enough to represent the whole genetic diversity of this species. Moreover, the low geographic differentiation in $P$. avium makes this determination difficult (Mariette et al, 1997; Mohanty et al, 2001).

The formation of $P$. cerasus and $P . \times$ gondouinii species both involved unreduced $P$. avium gametes. These abnormalities during meiosis occur at low frequencies and could be affected by genetic and environmental factors (Iezzoni and Hancock, 1984, 1996; Ramsey and Schemske, 1998). Nevertheless, we found two different groups of $P . \times$ goundouinii using A genome-specific markers. This suggests that the frequency of unreduced gamete production is sufficient to have led to two distinct hybridization events.

\section{Detection of genome-specific markers}

There are some limitations in our definition of genomespecific markers. Our sets of specific markers are stable with many P. avium samples (unpublished data), but the classification of markers was based on some unproven assumptions. The genetic diversity of $P$. avium has been shown to be weakly spatially structured (Mariette et al, 1997; Mohanty et al, 2001), but we have no data about impacts on the genetic diversity of any population bottleneck which could have accompanied the constitution of $P$. cerasus, nor the genetic drift since this constitution. Moreover, Beaver et al (1995) suggested that $P$. fruticosa, $P$. cerasus and $P$. avium share a common gene pool and/or are continually sharing alleles through introgression.

In each species, the genotypes studied in our sample did not represent the whole intraspecific genetic diversity. For example, P. cerasus analyzed in our sample were collected in French orchards and could originate from the same pool of progenitors. That is probably why the correspondence analysis, with only $\mathrm{A}$ and $\mathrm{F}$ genomespecific markers, respectively, did not reveal the clear genetic structure in P. cerasus, which has previously been reported (Iezzoni and Hancock, 1996).

To confirm that $\mathrm{F}$ genome-specific markers come from $P$. fruticosa, samples of this species should be genotyped. It would then be easier to classify each set of markers according to their presence or absence in each diploid 
species and in tetraploid species carrying the same genome: a procedure which has been successful in Gossypium (Abdalla et al, 2001).

A large number of crosses between species could occur within the genus Prunus and particularly within the subgenus Cerasus (Iezzoni et al, 1990; Webster, 1996). Backcrosses between P. cerasus and its progenitors exist. The four species $P$. avium, $P$. fruticosa, $P$. cerasus and $P . \times$ gondounii are often involved in many crosses with other species, even those from other botanical sections. For example, P. fruticosa could cross with Prunus canescens (Rehder, 1947). It would be very interesting to study all the Prunus subgenus Cerasus species, in order to analyse the genetic relationships between them and to have a better knowledge of the crosses involved.

\section{Acknowledgements}

We thank those who supplied plant samples, especially $\mathrm{R}$ Saunier, F Santi, M Leroux, M Dechaume, B Heinze, J Kleinschmidt, members of the Cytofor European program and members of the European and French networks for Prunus genetic resources. We also thank J Ronfort and $\mathrm{T}$ Bataillon for their comments on the manuscript. This work was supported by a grant from the 'Association Danone pour les Fruits', by a CEDRE project no. 99 Fb F12/L14.

\section{References}

Abdalla AM, Reddy OUK, ElZik KM, Pepper AE (2001) Genetic diversity and relationships of diploid and tetraploid cottons revealed using AFLP. Theor Appl Genet 102: 222-229.

Aggarwal RK, Brar DS, Nandi S, Huang N, Khush GS (1999). Phylogenetic relationships among Oryza species revealed by AFLP markers. Theor Appl Genet 98: 1320-1328.

Badenes ML, Parfitt DE (1995). Phylogenetic relationships of cultivated Prunus species from an analysis of chloroplast DNA variation. Theor Appl Genet 90: 1035-1041.

Baird WV, Ballard RE, Rajapakse S, Abbott AG (1996). Progress in Prunus mapping and application of molecular markers to germplasm improvement. Hortscience 31: 1099-1106.

Beaver JA, Iezzoni AF (1993). Allozyme inheritance in tetraploid sour cherry (Prunus cerasus L.). J Am Soc Hortic Sci 118: 873-877.

Beaver JA, Iezzoni AF, Ramm CW (1995). Isozyme diversity in sour, sweet, and ground cherry. Theor Appl Genet 90: 847-852.

Brettin TS, Karle R, Crowe EL, Iezzoni AF (2000). Chloroplast inheritance and DNA variation in sweet, sour, and ground cherry. J Hered 91: 75-79.

De Candolle A (1883). L'origine des plantes cultivées. Diderot Multimédia: Paris, pp 214-221 (edn 1998).

Faust M, Suranyi D (1997). Origin and dissemination of cherry. Hortic Rev 19: 263-317.

Hancock AM, Iezzoni AF (1988). Malate dehydrogenase isozyme patterns in seven Prunus species. Hortscience 23: 381-383.

Hedrick UP (1915). The history of cultivated cherries. In: Hedrick UP, Howe GH, Taylor OM, Tubergen CB, Wellington R (eds) The Cherries of New York. JB Lyon company: Albany, NY, pp 39-64.

Hillig KW, Iezzoni AF (1988). Multivariate analysis of a sour cherry germplasm collection. J Am Soc Hortic Sci 113: 928-934.

Iezzoni AF, Hancock AM (1996). Chloroplast DNA variation in sour cherry. Acta Hortic 410: 115-120.

Iezzoni AF, Mulinix CA (1992). Variation in bloom time in a sour cherry germplasm collection. Hortscience 27: 1113-1114.
Iezzoni AF, Schmidt H, Albertini A (1990). Cherries (Prunus). In: Moore JN, Bellington Jr JR (eds) Genetic Resources of Temperate Fruit and Nut Crops 1. International Society of Horticultural Science: Wageningen, pp 109-173.

Iezzoni AF, Hancock AM (1984). A comparison of pollen size in sweet and sour cherry. Hortscience 19: 560-562.

Jones CJ, Edwards KJ, Castaglione S, Winfield MO, Sala F, van de Wiel C et al (1997). Reproducibility testing of RAPD, AFLP and SSR markers in plants by a network of European laboratories. Mol Breeding 3: 381-390.

Krahl KH, Lansari A, Iezzoni AF (1991). Morphological variation within a sour cherry collection. Euphytica 52: 47-55.

Krussmann G (1978). Manual of Cultivated Broadleaved Trees and Shrubs, Vol. III. PRU-Z.B.T. Batsford Ltd: London, pp 18-58.

Mariette S, Lefranc M, Legrand P, Taneyhill D, Frascaria-Lacoste N, Machon N (1997). Genetic variability in wild cherry populations in France. Effects of colonizing processes. Theor Appl Genet 94: 904-908.

Mohanty A, Martin JP, Aguinagalde I (2001). A population genetic analysis of chloroplast DNA in wild populations of Prunus avium L. in Europe. Heredity 87: 421-427.

Nei M (1978). Estimation of average heterozygosity and genetic distance from a small number of individuals. Genetics 89: 583-590.

Olden EJ, Nybom N (1968). On the origin of Prunus cerasus L. Hereditas 70: 3321-3323.

Ramsey J, Schemske DW (1998). Pathways, mechanisms, and rates of polyploid formation in flowering plants. Ann Rev Ecol Syst 29: 467-501.

Rehder A (1947). Manual of Cultivated Trees and Shrubs, 2nd edn. Macmillan Company: New York, pp 452-481.

Santi F, Lemoine M (1990a). Genetic markers for Prunus avium L. 2: clonal identifications and discrimination from $P$. cerasus and P. cerasus $\times$ P. avium. Ann For Sci 47: 219-227.

Santi F, Lemoine M (1990b). Genetic markers for Prunus avium L. 1: inheritance and linkage of isozyme loci. Ann For Sci 47: 131-139.

SAS Intitute I (1985). SAS User's Guide: Statistics. Version 8 (Available at http://www.zi.unizh.ch/software/unix/statmath/sas/sasdoc/stat/).

Saunier R, Claverie J (2001). Le cerisier: évolution de la culture en France et dans le monde. Point sur les variétés, les portegreffe. Le fruit belge 490: 50-62.

Schueler S, Tusch A, Schuster M, Ziegenhagen B (2003). Characterization of microsatellites in wild and sweet cherry (Prunus avium L.). Markers for individual identification and reproductive processes. Genome 46: 95-102.

Schuster M, Schreiber H (2000). Genome investigation in sour cherry, P. cerasus L. Acta Horticulture 538: 375-379.

Viruel MA, Messeguer R, Vicente MCd, Garcia-Mas J, Pingdomenech P, Vargas F et al (1995). A linkage map with RFLP and isozyme markers for almond. Theor Appl Genet 91: 964-971.

Vos P, Hogers R, Bleeker M, Reijans M, van de Lee T, Hornes M et al (1995). AFLP: a new technique for DNA fingerprinting. Nucleic Acids Res 23: 4407-4414.

Webster AD (1996). The taxonomic classification of sweet and sour cherries and a brief history of their cultivation. In: Webster AD, Looney NE (eds) Cherries: Crop Physiology, Production and Uses. Cab International: Wallingford, pp 3-23.

Wunsch A, Hormaza JI (2002). Molecular characterization of sweet cherry (P. avium L.) genotypes using peach (Prunus persica L. Batsch) SSR sequences. Heredity 89: 56-63.

$\mathrm{Xu}$ M, Huaracha E, Korban SS (2001). Development of sequence-characterized amplified regions (SCARs) from amplified fragment length polymorphism (AFLP) markers tightly linked to the Vf gene in apple. Genome 44: 63-70. 